This is a self-archived version of an original article. This version may differ from the original in pagination and typographic details.

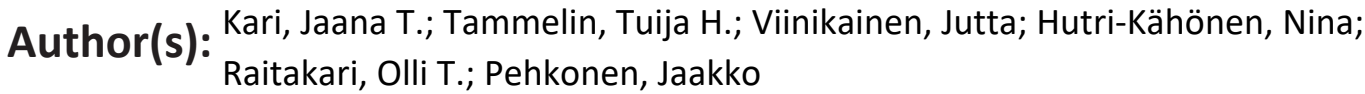

Title: Childhood Physical Activity and Adulthood Earnings

Year: 2016

Version: Published version

Copyright: 2016 by the Author(s).

Rights: CC BY-NC-ND 4.0

Rights url: https://creativecommons.org/licenses/by-nc-nd/4.0/

Please cite the original version:

Kari, J. T., Tammelin, T. H., Viinikainen, J., Hutri-Kähönen, N., Raitakari, O. T., \& Pehkonen, J.

(2016). Childhood Physical Activity and Adulthood Earnings. Medicine and Science in Sports and Exercise, 48(7), 1340-1346. https://doi.org/10.1249/MSS.0000000000000895 


\title{
Childhood Physical Activity and Adulthood Earnings
}

\author{
JAANA T. KARI ${ }^{1,2}$, TUIJA H. TAMMELIN ${ }^{1}$, JUTTA VIINIKAINEN ${ }^{2}$, NINA HUTRI-KÄHÖNEN ${ }^{3}$, \\ OLLI T. RAITAKARI ${ }^{4,5}$, and JAAKKO PEHKONEN ${ }^{2}$ \\ ${ }^{1}$ LIKES-Research Center for Sport and Health Sciences, Jyväskylä, FINLAND; ${ }^{2} J y v a s k y l a$ University School of Business and \\ Economics, Jyväskylä, FINLAND; ${ }^{3}$ Department of Pediatrics, Tampere University Hospital, University of Tampere, Tampere, \\ FINLAND; ${ }^{4}$ Research Centre of Applied and Preventive Cardiovascular Medicine, University of Turku, Turku, FINLAND; and \\ ${ }^{5}$ Department of Clinical Physiology and Nuclear Medicine, Turku University Hospital, Turku, FINLAND
}

\begin{abstract}
KARI, J. T., T. H. TAMMELIN, J. VIINIKAINEN, N. HUTRI-KÄHÖNEN, O. T. RAITAKARI, and J. PEHKONEN. Childhood Physical Activity and Adulthood Earnings. Med. Sci. Sports Exerc., Vol. 48, No. 7, pp. 1340-1346, 2016. Purpose: This study examined the associations between childhood physical activity level and adulthood earnings. Methods: The data were drawn from the ongoing longitudinal Young Finns Study, which was combined with register-based Finnish Longitudinal Employer-Employee Data and registerbased parents' background information from the Longitudinal Population Census of Statistics Finland. The study consisted of children who were $9 \mathrm{yr}$ ( $n=1257,52 \%$ boys), $12 \mathrm{yr}(n=1662,51 \%$ boys), and $15 \mathrm{yr}(n=1969,49 \%$ boys) of age at the time when physical activity was measured. The children were followed until 2010, when they were between 33 and $45 \mathrm{yr}$ old. Leisure-time physical activity in childhood was self-reported, whereas earnings in adulthood were register based and covered over a 10-yr period from 2000 to 2010. Ordinary least squares models were used to analyze the relationship between physical activity and earnings. Results: Childhood physical activity level was positively associated with long-term earnings among men $(P<0.001)$. In more detail, a higher level of leisure-time physical activity at the age of 9,12 , and $15 \mathrm{yr}$ was associated with an approximate $12 \%-25 \%$ increase in average annual earnings over a 10 -yr period. The results were robust to controlling, e.g., an individual's chronic conditions and body fat, parents' education and physical activity, and family income. Among women, no relation was observed. Conclusions: The findings provide evidence that childhood physical activity can have far-reaching positive effects on adulthood earnings. Possibilities for improving physical activity during childhood may not only promote health but also affect long-term labor market outcomes. Key Words: EARNINGS, PHYSICAL ACTIVITY, CHILDHOOD, REGISTER-BASED DATA
\end{abstract}

$\Lambda$ ccording to current physical activity recommendations for health, only one-third of the youth are estimated to be sufficiently active $(9,13)$. Besides the widely acknowledged positive health effects of physical activity $(22,24,27,29,40)$, physical inactivity has been identified as the fourth leading risk factor for global mortality (39), and several studies have reported increasing healthcare costs due to physical inactivity $(7,15,16,18,22)$.

\footnotetext{
Address for correspondence: Jaana T. Kari, M.Sc., LIKES—Research Center for Sport and Health Sciences, Viitaniementie 15a, 40720 Jyväskylä, Finland; E-mail: jaana.kari@likes.fi.

Submitted for publication September 2015.

Accepted for publication January 2016.

Supplemental digital content is available for this article. Direct URL citations appear in the printed text and are provided in the HTML and PDF versions of this article on the journal's Web site (www.acsm-msse.org).

0195-9131/16/4807-1340/0

MEDICINE \& SCIENCE IN SPORTS \& EXERCISE

Copyright $(0) 2016$ by the Author(s). Published by Wolters Kluwer Health on behalf of the American College of Sports Medicine. This is an openaccess article distributed under the terms of the Creative Commons AttributionNon Commercial-No Derivatives License 4.0 (CCBY-NC-ND), where it is permissible to download and share the work provided it is properly cited. The work cannot be changed in any way or used commercially.
}

DOI: 10.1249 /MSS.0000000000000895
In addition to the positive correlation with health, physical activity has also been linked to positive returns in the labor market. There is evidence that former high school and college athletes $(5,10,11,23,36)$ as well as those who are physically active in adulthood $(14,17,19-21,31)$ typically perform better in the labor market in terms of wages $(5,10,11,19,23,31)$ and employment probability $(17,36)$. For example, using information from a long-term perspective, Lechner (20) and Rooth (31) showed that physical activity was positively related to monthly earnings and hourly wages, and Hyytinen and Lahtonen (14) reported similar results for men on the basis of twin data. According to a field experiment conducted by Rooth (31), employees also interpreted physical activity as a positive signal; that is, the probability of receiving a callback for a job interview was higher for those who announced to be physically active. Stevenson (36), in turn, argued that the positive association between physical activity and wages existed solely because of the increase in labor force participation.

Although a positive connection between physical activity and labor market outcomes has been established, the reason for this correlation is unclear. One possibility is that higher physical activity leads to health gains, which, in turn, increase worker productivity and, therefore, labor market returns $(20,21)$. Productivity gains can arise, for example, from 
decreased absences due to sickness or from better performance by workers. It is also possible that physical activity facilitates networking, which promotes career development (20). Additionally, physical activity may develop noncognitive skills, such as teamwork skills, sociability, or discipline $(1,3,4,10)$, which are rewarded in the labor market. Finally, physical activity can cause positive discrimination (26,31), which may explain success in individuals' work lives.

Increasing evidence suggests that physical activity is related to substantial economic and noneconomic returns. The benefits of physical activity not only are confined to health but may also cover other areas such as labor market performance. The purpose of this study was to examine the associations between childhood physical activity and earnings in adulthood. We hypothesized that higher physical activity level in childhood is associated with higher earnings in adulthood. Previous literature concerning the relationship between physical activity and labor market outcomes has mainly focused on physical activity during adulthood or adolescence. However, the role of physical activity in childhood is particularly relevant for two reasons. First, because childhood physical activity is measured before any labor market experience, the potential problem of reverse causality is eliminated. Second, if physical activity in childhood has far-reaching implications for future work life, this could be taken into account by policy makers. In general, possibilities for improving labor force's productivity are important because higher productivity increases economic welfare and strengthens competitiveness (21).

\section{METHODS}

Study population. The data were drawn from the ongoing longitudinal Young Finns Study (YFS), which was launched in 1980, when 3596 (82.3\%) of the 4326 invited individuals in six age cohorts (age 3, 6, 9, 12, 15, and $18 \mathrm{yr}$ ) participated in the baseline study. The participants were randomly chosen boys (51\%) and girls (49\%) from five Finnish university cities (Helsinki, Turku, Tampere, Oulu, and Kuopio) and their rural surroundings. The study has been conducted in seven follow-up phases, and the most recent follow-up was performed in 2011/2012. The examinations included comprehensive data collection using questionnaires, physical measurements, and blood tests as previously described (28). The research protocol for the YFS was approved by the ethics committees of the five universities (Helsinki, Turku, Tampere, Oulu, and Kuopio), and written informed consent was obtained before respondents participated in the study. Moreover, data protection issues have been taken into account as specified in current Finnish legislation.

The YFS was then linked to register-based Finnish Longitudinal Employer-Employee Data (FLEED) from Statistics Finland. FLEED records detailed information on labor market outcomes, and covers the period from 1990 to 2010. Register-based information on family background was obtained from the Longitudinal Population Census of Statistics Finland from 1980. FLEED and the Longitudinal Population Census were linked to the YFS based on unique personal identifiers. This is exact matching and therefore avoids problems created by errors in record linkages (30).

The present study consisted of children who were $9 \mathrm{yr}$ ( $n=1257,52 \%$ boys), $12 \mathrm{yr}(n=1662,51 \%$ boys $)$, and $15 \mathrm{yr}(n=1969,49 \%$ boys $)$ of age when the information about physical activity was collected. These individuals were followed until 2010, when they were between 33 and $45 \mathrm{yr}$ old. The original 9-yr-old participants were born in 19711977, the 12-yr-old participants in 1968-1977, and the 15-yrold participants in 1965-1977.

Self-reported physical activity. Leisure-time physical activity at the age of 9,12 , and $15 \mathrm{yr}$ was measured with a self-reported questionnaire. The questions concerned the frequency and intensity of leisure-time physical activity, participation in sports club training, participation in sport competitions, and habitual way of spending leisure-time $(37,38)$. The response alternatives were coded from 1 to 3 , except participation in sport competition, which was coded from 1 to 2, and thereafter summed to form a physical activity index (PAI) with scores ranging from 5 to 14 (see Table, Supplemental Digital Content 1, original scoring and recoding of the items included in PAI in 1980-1989, range from 5 to 14 [37], http://links.lww.com/MSS/A648).

Register-based annual earnings. Information on annual earnings was drawn from FLEED, which records information on annual wage and salary earnings from tax authority registers. The earnings were measured as a logarithm of the average annual wages and salary earnings from 2000 to 2010 . The values were deflated using the consumer price index (base year 2000).

Statistical analyses. STATA software, version 13.1, was used for the statistical analyses. The analysis was based on the ordinary least squares (OLS) models, where the associations between childhood physical activity and later labor market returns were regressed by using the logarithm of the average annual wages and salaries as the dependent variable and the PAI at the age of 9,12 , or $15 \mathrm{yr}$ as an explanatory variable. All baseline models controlled for the birth cohort and the birth month, which are both predetermined variables. Before the OLS models, the correlation coefficients were calculated to illustrate the unconditional connections between childhood physical activity and earnings in adulthood.

The consistency and the robustness of the OLS estimator require that the physical activity variable and observed confounding variables are uncorrelated with the error term and that unobserved individual heterogeneity is uncorrelated with the physical activity variable. We supported these assumptions with several methods. First, following Angrist and Pischke (p. 68 [2]), all confounding variables in the baseline models were obtained before labor market entry. Thus, future labor market outcomes cannot have an effect on the confounders measured before labor market entry. Second, it is possible that childhood physical activity reflects 


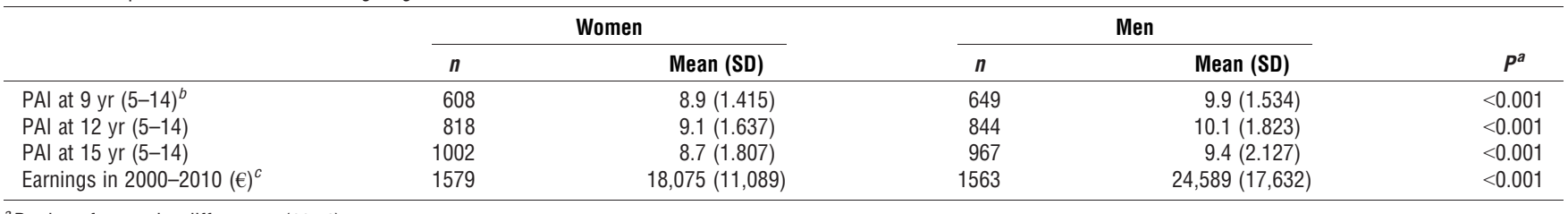

${ }^{a} P$ values for gender differences ( $t$-test)

${ }^{D}$ The PAl (scale 5 to 14) is a summary of five variables that illustrate the frequency and intensity of leisure-time physical activity, frequency of participation in sports clubs training, participation in sport competitions, and the most common activity during leisure time.

${ }^{c}$ Earnings illustrate the logarithm of the average of the annual wage and salary earnings over the period 2000-2010. The values are deflated using the consumer price index (base year 2000).

omitted variables without having an independent effect on later labor market outcomes. To alleviate this problem, the models were extended by several additional covariates. First, the models were augmented with individuals' chronic diseases and body fat obtained in 1980 (34). Second, several family background variables obtained in 1980 (parents' education, family income, parents' health, and parents' physical activity) were added as controls.

As a robustness check, the baseline models were extended in three ways. First, the sample size of the baseline models varied depending on the age when the PAI was measured. Thus, the difference between the point estimates at the age of 9,12 , and $15 \mathrm{yr}$ might partly reflect the differences in the sample. To control for this possibility, the sample size was locked up to those born in $1971(n=447$ men and $n=437$ women) and whose physical activity levels were measured at all three time points (at the age of 9, 12, and $15 \mathrm{yr}$ ). Although this method reduced the sample size, the same participants could be tracked during the entire period. Second, we investigated whether the association between physical activity and earnings is due to more intense labor market attachment of individuals who were more physically active. This was done by controlling individual average employment months during 2000-2010, and thereby the possibility that the results are driven by unemployment or labor market inactivity could be considered. Finally, we tested whether taking into account the quality of the leisure-time physical activity affects the results. This was done by dividing the original PAI into two parts: a variable that indicated participation in sport competitions $(1=$ participates in national or regional level sport competitions, $0=$ does not participate in sport competitions) and the original PAI subtracted from the sport competition variable. The original PAI was replaced with these two new variables in the wage equation.

\section{RESULTS}

Baseline results. In all age groups $(9,12$, and $15 \mathrm{yr})$, girls had lower physical activity levels compared with boys $(P<$ 0.001 , Table 1). Similarly, the average annual earnings in 2000 2010 were lower among women compared with men $(P<$ 0.001). According to the correlation coefficients, among men, the physical activity level in childhood was positively associated with earnings in adulthood $(P<0.001$, Table 2$)$, whereas no significant correlation was observed among women.
The baseline OLS estimates (Table 3, column 1) indicated that, among men, higher physical activity at the age of 9,12 , and $15 \mathrm{yr}$ was associated with higher earnings. In terms of standardized coefficients, one SD increase in the PAI at the age of $9 \mathrm{yr}$ was related to approximately 38\% higher longterm earnings, over a 10 -yr period, whereas the standardized coefficient for the PAI at the age of 12 and $15 \mathrm{yr}$ was approximately $29 \%$. Unlike what was hypothesized, among women (Table 4, column 1), no such relation was observed.

The inclusion of a comprehensive set of potential confounding factors (Tables 3 and 4, columns 2, 3, and 4) kept the physical activity estimate by and large intact. When individual and family background factors were controlled (Table 3, column 4), one SD increase in the PAI at the age of 9,12 , and $15 \mathrm{yr}$ was related to an approximate $30 \%$ increase in adulthood earnings among men.

Robustness checks. The results remained intact when the sample size was restricted to individuals ( $n=447$ boys and 437 girls) whose physical activity levels were followed at three time points (at the age of 9,12 , and $15 \mathrm{yr}$ ) during childhood. Among men, one SD increase in the PAI at the age of 9,12 , and $15 \mathrm{yr}$ was related to an approximate $30 \%$ increase in long-term earnings over a 10 -yr period. Among women, no association was observed, which is in line with the baseline OLS results.

After controlling for a person's employment months in 2000-2010, childhood physical activity at the age of 12 and $15 \mathrm{yr}$ was positively related to men's earnings (Table 5, column 1). However, the point estimate decreased indicating that one SD increase in the PAI at the age of 12 and $15 \mathrm{yr}$

TABLE 2. Correlation coefficients.

\begin{tabular}{|c|c|c|c|c|}
\hline & PAI $9^{a}$ & PAI $12^{b}$ & PAI $15^{c}$ & Earnings $2000-2010^{d}$ \\
\hline \multicolumn{5}{|l|}{ Women } \\
\hline PAI 9 & - & & & \\
\hline PAI 12 & $0.490^{\star * *}$ & - & & \\
\hline PAl 15 & $0.261^{\star \star *}$ & $0.456^{\star * *}$ & - & \\
\hline Earnings 2000-2010 & 0.032 & 0.012 & 0.028 & - \\
\hline \multicolumn{5}{|c|}{ Men } \\
\hline PAI 9 & - & & & \\
\hline PAI 12 & $0.530^{\star * *}$ & - & & \\
\hline PAI 15 & $0.424^{\star \star *}$ & $0.574^{\star * *}$ & - & \\
\hline Earnings 2000-2010 & $0.127^{* *}$ & $0.080^{\star}$ & $0.120^{\star * *}$ & - \\
\hline \multicolumn{5}{|c|}{$\begin{array}{l}\text { The level of statistical significance: }{ }^{*} P<0.05,{ }^{* *} P<0.01,{ }^{* *} P<0.001 \text {. } \\
{ }^{a} \text { The PAl at the age of } 9 \mathrm{yr} \text {. } \\
{ }^{{ }^{*}} \text { The PAl at the age of } 12 \mathrm{yr} \text {. } \\
{ }^{c} \text { The PAl at the age of } 15 \mathrm{yr} \text {. } \\
{ }^{d} \text { Earnings illustrate the logarithm of the average of the annual wage and salary earnings } \\
\text { over the period of } 2000-2010 \text {. The values are deflated using the consumer price index } \\
\text { (base year 2000). }\end{array}$} \\
\hline
\end{tabular}




\begin{tabular}{|c|c|c|c|c|c|}
\hline & \multicolumn{5}{|c|}{ In(Earnings 2000-2010) } \\
\hline & 1 & 2 & 3 & 4 & $5(N=447)$ \\
\hline $\begin{array}{l}\text { PAI } 9^{b} \\
N=649\end{array}$ & $\begin{array}{c}0.246^{\star * \star} \\
(0.059)\end{array}$ & $\begin{array}{c}0.204^{\star * *} \\
(0.055)\end{array}$ & $\begin{array}{c}0.236^{* * *} \\
(0.062)\end{array}$ & $\begin{array}{c}0.194^{\star * \star *} \\
(0.058)\end{array}$ & $\begin{array}{c}0.202^{* * *} \\
(0.064)\end{array}$ \\
\hline$R^{2}$ & 0.04 & 0.14 & 0.06 & 0.16 & 0.23 \\
\hline PAI 12 & $0.159^{\star \star \star}$ & $0.148^{\star \star \star}$ & $0.165^{\star \star \star}$ & $0.160^{\star \star \star}$ & $0.175^{\star \star \star}$ \\
\hline$N=844$ & $(0.048)$ & $(0.047)$ & $(0.048)$ & $(0.046)$ & $(0.053)$ \\
\hline$R^{2}$ & 0.03 & 0.012 & 0.05 & 0.14 & 0.23 \\
\hline PAI 15 & $0.135^{\star \star \star}$ & $0.124^{\star \star *}$ & $0.138^{* * *}$ & $0.126^{\star * *}$ & $0.152^{* * *}$ \\
\hline$N=967$ & $(0.035)$ & $(0.034)$ & $(0.036)$ & $(0.035)$ & $(0.052)$ \\
\hline$R^{2}$ & 0.02 & 0.12 & 0.03 & 0.13 & 0.23 \\
\hline \multicolumn{6}{|l|}{ Control variables } \\
\hline Cohort $^{c}$ & $x$ & $x$ & $x$ & $x$ & $x$ \\
\hline Month of birth & $x$ & $x$ & $x$ & $x$ & $x$ \\
\hline Individual characteristics ${ }^{d}$ & & $x$ & & $x$ & $x$ \\
\hline Family characteristics ${ }^{e}$ & & & $x$ & $x$ & $x$ \\
\hline
\end{tabular}

The level of significance: ${ }^{* \star \star} P<0.001$. Unstandardized coefficients. Robust SE values are in parentheses.

${ }^{a}$ Earnings are deflated using the consumer price index (base year 2000).

${ }^{b}$ PAI 9, PAI 12, and PAI 15 illustrate the self-reported leisure-time physical activity at the age of 9, 12, and $15 \mathrm{yr}$.

${ }^{c}$ Cohort dummies illustrate the year of birth: cohort $1=$ born in 1962, cohort $2=$ born in 1965 , cohort $3=$ born in 1968, cohort $4=$ born in 1971 , cohort $5=$ born in 1974 , cohort $6=$ born in 1977.

${ }^{d}$ Individual characteristics include health and body fat (Slaughter equation). Health was controlled by using indicators for the following diseases: allergy/asthma, diabetes, convulsions, heart defect, infectious and parasitic diseases, tumors, endocrine diseases/metabolic disorders/malnutrition, blood disorders, mental disturbances, nervous and sensory system diseases, circulatory system diseases, respiratory diseases, digestive system diseases, genital and urinary tract diseases, skin and subcutaneous tissue diseases, musculoskeletal disorders, and other unidentified symptoms.

'Family background factors included parents' education, family income, parents' health, and parents' physical activity obtained in 1980.

was related to an approximate $6 \%-7 \%$ increase in long-term earnings. Among women, the physical activity level at the age of 15 yr turned significant after controlling for employment (Table 5, column 2). In this specification, one SD increase in the PAI was related to an approximate $6 \%$ increase in adulthood earnings.

The results from the models where the original PAI was divided into leisure-time physical activity and participation in sport competitions are reported in Table 6. After controlling for leisure-time physical activity, participation in sport competitions at the age of $9 \mathrm{yr}$ was related to higher earnings among men. At ages 12 and $15 \mathrm{yr}$, only the leisuretime physical activity remained significant and positive.
Among women (Table 6, columns 3 and 4), no such relation was found. The results were robust to the inclusion of an individual's chronic diseases, body fat, and family background factors (Table 6, columns 2 and 4).

\section{DISCUSSION}

In summary, using a longitudinal population-based cohort study combined with register-based information on labor market outcomes, this study investigated the relationship between childhood physical activity and long-term earnings. The results showed that, among men, self-reported physical activity in childhood was related to higher long-term

TABLE 4. Regression analysis of long-term earnings among women.

\begin{tabular}{|c|c|c|c|c|c|}
\hline & \multicolumn{5}{|c|}{ In(Earnings 2000-2010) ${ }^{a}$} \\
\hline & 1 & 2 & 3 & 4 & $5(N=437)$ \\
\hline PAI $9^{b}$ & 0.060 & 0.058 & 0.056 & 0.056 & 0.061 \\
\hline$N=608$ & $(0.048)$ & $(0.049)$ & $(0.047)$ & $(0.048)$ & $(0.055)$ \\
\hline$R^{2}$ & 0.03 & 0.06 & 0.07 & 0.09 & 0.10 \\
\hline PAl 12 & 0.026 & 0.023 & 0.020 & 0.017 & 0.014 \\
\hline$N=818$ & $(0.034)$ & $(0.034)$ & $(0.035)$ & $(0.034)$ & $(0.045)$ \\
\hline$R^{2}$ & 0.03 & 0.05 & 0.05 & 0.07 & 0.09 \\
\hline PAI 15 & 0.045 & 0.052 & 0.022 & 0.029 & 0.016 \\
\hline$N=1002$ & $(0.029)$ & $(0.027)$ & $(0.029)$ & $(0.028)$ & $(0.035)$ \\
\hline$R^{2}$ & 0.03 & 0.07 & 0.06 & 0.10 & 0.09 \\
\hline \multicolumn{6}{|l|}{ Control variables } \\
\hline Cohort $^{c}$ & $x$ & $x$ & $x$ & $x$ & $x$ \\
\hline Month of birth & $x$ & $x$ & $x$ & $x$ & $x$ \\
\hline Individual characteristics ${ }^{d}$ & & $x$ & & $x$ & $x$ \\
\hline Family characteristics ${ }^{e}$ & & & $x$ & $x$ & $x$ \\
\hline
\end{tabular}

Unstandardized coefficients. Robust SE values are in parentheses.

${ }^{a}$ Earnings are deflated using the consumer price index (base year 2000).

bPAI 9, PAI 12, and PAI 15 illustrate the self-reported leisure-time physical activity at the age of 9, 12, and $15 \mathrm{yr}$.

${ }^{c}$ Cohort dummies illustrate the year of birth: cohort $1=$ born in 1962, cohort $2=$ born in 1965 , cohort $3=$ born in 1968 , cohort $4=$ born in 1971 , cohort $5=$ born in 1974 , cohort $6=$ born in 1977.

${ }^{d}$ Individual characteristics include health and body fat (Slaughter equation). Health was controlled by using indicators for the following diseases: allergy/asthma, diabetes, convulsions, heart defect, infectious and parasitic diseases, tumors, endocrine diseases/metabolic disorders/malnutrition, blood disorders, mental disturbances, nervous and sensory system diseases, circulatory system diseases, respiratory diseases, digestive system diseases, genital and urinary tract diseases, skin and subcutaneous tissue diseases, musculoskeletal disorders, and other unidentified symptoms.

${ }^{e}$ Family background factors included parents' education, family income, parents' health, and parents' physical activity obtained in 1980. 
TABLE 5. Robustness check, labor market attachment.

\begin{tabular}{|c|c|c|}
\hline & \multicolumn{2}{|c|}{ In(Earnings 2000-2010) } \\
\hline & Men & Women \\
\hline PAI $9^{b}$ & $0.036(0.023)$ & $0.007(0.017)$ \\
\hline$R^{2}$ & 0.53 & 0.61 \\
\hline PAl 12 & $0.036^{\star \star *}(0.014)$ & $0.004(0.013)$ \\
\hline$R^{2}$ & 0.53 & 0.56 \\
\hline PAl 15 & $0.026^{\star \star}(0.012)$ & $0.038^{* * *}(0.011)$ \\
\hline$R^{2}$ & 0.52 & 0.52 \\
\hline \multicolumn{3}{|l|}{ Control variables } \\
\hline Cohort $^{c}$ & $x$ & $x$ \\
\hline Month of birth & $x$ & $x$ \\
\hline Employment months in $2000-2010^{d}$ & $x$ & $x$ \\
\hline
\end{tabular}

The level of significance: ${ }^{* *} P<0.01,{ }^{* *} P<0.001$. Unstandardized coefficients. Robust SE values are in parentheses.

${ }^{a}$ Earnings are deflated using the consumer price index (base year 2000).

${ }^{b} \mathrm{PAI} 9$, PAI 12, and PAI 15 illustrate the self-reported leisure-time physical activity at the age of 9,12 , and $15 \mathrm{yr}$.

${ }^{c}$ Cohort dummies illustrate the year of birth: cohort $1=$ born in 1962, cohort $2=$ born in 1965 , cohort $3=$ born in 1968 , cohort $4=$ born in 1971 , cohort $5=$ born in 1974 , cohort $6=$ born in 1977 .

${ }^{d}$ The average of the annual employment months in 2000-2010. Additionally, the results remained intact when a predetermined variable (the average of the employment months in 1999) was added.

earnings in adulthood. Among women, no such relation was observed.

The linked data and longitudinal setting of the study extend the previous literature in three important ways. First, adulthood physical activity can be shaped by success or failure in the labor market, which can make the direction of the causality between physical activity and earnings unclear (e.g., $[8,14,20])$. We overcame this problem by using measures of physical activity during childhood, before labor market entry. Second, instead of cross-sectional information on earnings, which contains idiosyncratic components and is often an inaccurate proxy for long-term earnings (e.g., $[6,12])$, this study used the average earnings measured over a 10 -yr period as the dependent variable. The information on earnings was also register based, and therefore, potential bias resulting from self-reported information can be ignored.
However, the physical activity measurements were obtained with a self-reported questionnaire, and thus, there may be some measurement error $(32,33)$. Finally, to mitigate the possibility that unobserved characteristics, such as family background factors or preexisting differences in health and physical features, drive the results, we used individuals' chronic diseases, body fat, and several indicators for family background as control variables.

Our results showed that the childhood physical activity level was positively related to earnings among men. The results were robust to controlling for individual and family background factors. Among women, no association between physical activity and earnings was observed. When an individual's employment months were controlled, the physical activity point estimate decreased. This implies that the connection between physical activity and earnings can be partly attributed to the more intense labor market attachment of physically active individuals; that is, they experience less unemployment or their labor market participation is higher. A possible explanation for the positive association between physical activity and earnings is that some unobserved traits are related to physical activity and earnings. Such traits could be ambition, competitiveness, or target orientations, which may be more prevalent among competitive athletes. To test this possibility, the original PAI was divided into leisure-time physical activity and participation in sport competitions. However, our results did not support the assumption that competitive children would receive higher earnings once the leisure-time physical activity was controlled.

Our findings are consistent with previous literature in which adulthood physical activity has been associated with higher earnings $(5,10,11,14,20,23,31,36)$. However, all previous studies investigated the role of adulthood physical activity or physical activity in adolescence, and none focused on childhood physical activity, especially outside school hours. In addition, the questions concerning the level of physical

TABLE 6. Robustness check, leisure-time physical activity vs target-oriented physical activity.

\begin{tabular}{|c|c|c|c|c|}
\hline & \multicolumn{4}{|c|}{ In(Earnings 2000-2010) } \\
\hline & \multicolumn{2}{|c|}{ Men } & \multicolumn{2}{|c|}{ Women } \\
\hline & 1 & 2 & 3 & 4 \\
\hline PA $9^{b}$ & $0.133^{*}(0.079)$ & $0.105(0.076)$ & $0.015(0.050)$ & $0.012(0.054)$ \\
\hline $\mathrm{COM} 9^{c}$ & $0.402^{* *}(0.186)$ & $0.329 *(0.076)$ & $0.184(0.156)$ & $0.188(0.175)$ \\
\hline$R^{2}$ & 0.05 & 0.19 & 0.03 & 0.10 \\
\hline PA 12 & $0.143^{* *}(0.062)$ & $0.109^{*}(0.063)$ & $-0.021(0.045)$ & $-0.020(0.052)$ \\
\hline COM 12 & $0.037(0.195)$ & $0.174(0.205)$ & $0.143(0.132)$ & $0.095(0.146)$ \\
\hline$R^{2}$ & 0.03 & 0.17 & 0.03 & 0.08 \\
\hline PA 15 & $0.128^{* *}(0.058)$ & $0.148^{\star \star}(0.063)$ & $0.058(0.038)$ & $0.028(0.043)$ \\
\hline COM 15 & $0.175(0.235)$ & $0.018(0.234)$ & $-0.044(0.171)$ & $-0.033(0.174)$ \\
\hline$R^{2}$ & 0.04 & 0.18 & 0.02 & 0.11 \\
\hline \multicolumn{5}{|l|}{ Control variables } \\
\hline Cohort & $x$ & $x$ & $x$ & $x$ \\
\hline Month of birth & $x$ & $x$ & $x$ & $x$ \\
\hline Individual characteristics & & $x$ & & $x$ \\
\hline Family characteristics & & $x$ & & $x$ \\
\hline
\end{tabular}

The level of significance: ${ }^{\star} P<0.05,{ }^{\star \star} P<0.01$. Unstandardized coefficients. Robust SE values are in the parentheses.

${ }^{a}$ Earnings are deflated using the consumer price index (base year 2000).

${ }^{b}$ PA 9, PA 12, and PA 15 illustrate the self-reported leisure-time physical activity at the age of 9 , 12, and 15 yr excluding the participation in sport competitions.

${ }^{c}$ Participation in sports competitions (COM) is a binary variable that gets a value of 1 if individual participates in national or regional level sport competitions and 0 otherwise.

${ }^{d}$ Cohort dummies illustrate the year of birth: cohort $1=$ born in 1962, cohort 2 = born in 1965 , cohort $3=$ born in 1968 , cohort $4=$ born in 1971 , cohort $5=$ born in 1974 , cohort $6=$ born in 1977. 
activity were study specific. This study focused on leisuretime physical activity outside school hours, whereas most of the previous studies focused on the frequency of physical activity $(14,17,19,20)$, or high school athletic participation $(5,10,11,23,36)$. Therefore, the comparison between the results is not straightforward. Nevertheless, our results add to the current literature by showing that the association between physical activity and labor market performance may start to develop as early as in childhood.

One notable feature is the difference between the results for men and women. The association was significant only among men. This finding is in line with the study by Hyytinen and Lahtonen (14) who reported 14\%-17\% higher long-term income of physically active men than that of the less active men. Similarly, a study by Long and Caudill (23) showed that men who participated in intercollegiate athletics had higher annual income compared with nonathletes, whereas among women, no such income premium was found. Lechner (20) and Kosteas (19), in contrast, found a significant positive relationship between adulthood physical activity and earnings for men and women. Finally, Stevenson (36) demonstrated a positive association between increased opportunities to participate in sports and subsequent wages among women. The connection between physical activity and earnings seems to be positive and robust among men, but for women, the results are less clear. The differences in the labor force participation between fertility-age men and women might partly explain the results. Our results indirectly support this hypothesis because a positive association between physical activity and earnings was found among women when the employment months were controlled.

Although the study demonstrated a positive association between physical activity and earnings, the causality cannot be interpreted. An apparent threat to the causal interpretation is that some unobserved characteristics are correlated with physical activity and earnings. Intuitively, however, childhood physical activity may promote adulthood labor market performance for four reasons. First, childhood physical activity can lead to health gains, which are rewarded later in working life with higher productivity and higher earnings. According to Smith (35) and Lundborg et al. (25), poor health in adolescence had a substantial effect on earning in

\section{REFERENCES}

1. Alchian A, Harold D. Production, information costs, and economic organization. Am Econ Rev. 1972;62:777-95.

2. Angrist JD, Pischke JS. Mostly Harmless Econometrics: An Empiricist's Companion. Princeton: Princeton University Press; 2009. p. 68.

3. Bailey R. Evaluating the relationship between physical education, sport and social inclusion. Educ Rev. 2005;57:71-90.

4. Bailey R, Armour K, Kirk D, Jess M, Pickup I, Sandford R. The educational benefits claimed for physical education and school sport: an academic review. Res Pap Educ. 2009;24:1-27.

5. Barron JM, Ewing BT, Waddel GR. The effects of high school athletic participation on education and labor market outcomes. Rev Econ Stat. 2000;82(3):409-21. adulthood, whereas Lechner (20) showed that adulthood physical activity had a sizable positive effect on health and long-term earnings. Second, physical activity in childhood (e.g., participation in sports competitions) may create networks, which promote career development (20), and therefore is positively associated with earnings in adulthood. Third, physical activity may improve noncognitive skills, such as teamwork skills, sociability, or discipline $(1,3,4,10)$, which contribute later in the labor markets. Fourth, physical activity might serve as a signal to employers of good health, motivation, ambition, and productivity, and therefore causes positive discrimination $(26,31)$, which explains the wage gap.

Only one-third of the youth are sufficiently active and meet current physical activity guidelines $(9,13)$. As this study suggests, the consequences of childhood physical activity can be far reaching. Physical activity might not only promote health but also affect labor market outcomes later in life. From policy perspective, the findings are twofold: If childhood physical activity can boost an individual's labor productivity, increasing participation in physical activities during the life course may constitute an important policy goal. Second, encouraging children to be physically active, providing children equal possibilities to participate in physical activities regardless of their socioeconomic background, and targeting interventions to children and youth with the lowest physical activity levels should become an important policy objective. To further increase understanding of this association, it would be valuable to explore the potential mechanism in more detail. In addition, understanding the role of physical activity in other dimensions of labor market performance, such as unemployment and occupational sorting, could shed light on the results.

This study was funded by the Finnish Ministry of Education and Culture, Juho Vainio Foundation, and Yrjö Jahnsson Foundation (6646). The YFS has been financially supported by the Academy of Finland: grants 134309 (Eye), 126925, 121584, 124282, 129378 (Salve), 117797 (Gendi), and 41071 (Skidi); the Social Insurance Institution of Finland; Kuopio, Tampere, and Turku University Hospital Medical Funds; Juho Vainio Foundation; Sigrid Juselius Foundation; Paavo Nurmi Foundation; Finnish Foundation of Cardiovascular Research and Finnish Cultural Foundation, Tampere Tuberculosis Foundation; and Emil Aaltonen Foundation.

The authors declare no conflicts of interest.

The results of the present study do not constitute endorsement by the American College of Sports Medicine.

6. Böhlmark A, Lindquist M. Life-cycle variations in the association between current and lifetime income: replication and extension for Sweden. J Labour Econ. 2006;24(4):879-900.

7. Colditz G. Economic costs of obesity and inactivity. Med Sci Sports Exerc. 1999;31(11):S663-7.

8. Cutler DM, Glaeser E. What explains differences in smoking, drinking, and other health-related behaviors? Am Econ Rev. 2005;95(2):238-42.

9. Ekelund U, Tomkinson G, Armstrong N. What proportion of youth are physically active? Measurement issues, levels and recent time trends. Br J Sports Med. 2011;45:859-65.

10. Ewing BT. Athletes and work. Econ Lett. 1998;59:113-7. 
11. Ewing BT. The labor market effects of high school athletic participation: evidence from wage and fringe benefit differentials. JSE. 2007;8:255-65.

12. Haider S, Solon G. Life-cycle variation in the association between current and lifetime earnings. Am Econ Rev. 2006;96(4):1308-20.

13. Hallal PC, Andersen LB, Bull FC, et al. Global physical activity levels: surveillance progress, pitfalls, and prospects. Lancet. 2012;380:247-57.

14. Hyytinen A, Lahtonen J. The effect of physical activity on longterm income. Soc Sci Med. 2013;96:129-37.

15. Katzmarzyk PT, Gledhill N, Shephard RJ. The economic burden of physical inactivity in Canada. CMAJ. 2000;163:1435-40.

16. Katzmarzyk PT, Janssen I. The economic costs associated with physical inactivity and obesity in Canada: an update. Can J Appl Physiol. 2004;29:90-115.

17. Kavetsos G. The impact of physical activity on employment. J Socio Econ. 2011;40:775-9.

18. Kohl HW 3rd, Craig CL, Lambert EV, et al. The pandemic of physical inactivity: global action for public health. Lancet. 2012;380(9838):294-305.

19. Kosteas V. The effect of exercise on earnings: evidence from the NLSY. J Labor Res. 2012;33:225-50.

20. Lechner M. Long-run labour market and health effects of individual sports activities. $J$ Health Econ. 2009;28:839-54.

21. Lechner M. Sports, exercise, and labor market outcomes. IZA World Labor. 2015:126.

22. Lee IM, Shiroma EJ, Lobelo F, Puska P, Blair SN, Katzmarzyk PT. Effect of physical inactivity on major non-communicable diseases worldwide: an analysis of burden of disease and life expectancy. Lancet. 2012;380(9838):219-29.

23. Long JE, Caudill SB. The impact of participation in intercollegiate athletics on income and graduation. Rev Econ Stat. 1991;73:525-31.

24. Luepker R, Johnson S, Breslow L, et al. Physical activity and cardiovascular health. JAMA. 1996;276(3):241-6.

25. Lundborg P, Nilsson A, Rooth DO. Adolescent health and adult labor market outcomes. $J$ Health Econ. 2014;37:25-40.

26. McCormick R, Maurice T. Athletics versus academics? Evidence from SAT scores. J Polit Econ. 1987;95:1103-16.

27. Murray C, Lopez A. Global mortality, disability, and the contribution of risk factors: global burden of disease study. Lancet. 1997;349:1436-42.
28. Raitakari OT, Juonala M, Rönnemaa T, et al. Cohort profile: the Cardiovascular Risk in Young Finns Study. Int $J$ Epidemiol. 2008;37:1220-6.

29. Raitakari OT, Taimela S, Porkka KV, et al. Associations between physical activity and risk factors for coronary heart disease: the Cardiovascular Risk in Young Finns Study. Med Sci Sports Exerc. 1997;29(8):1055-61.

30. Ridder G, Moffitt R. The econometrics of data combination. In: Heckman JJ, Leamer EE, editors. Handbook of Econometrics. Vol. 6, Part B. Amsterdam: North-Holland, Elsevier Science; 2007. pp. 5469-547.

31. Rooth DO. Work out or out of work - the labor market return to physical fitness and leisure sports activities. Labour Econ. 2011; 18:399-409.

32. Sallis JF, Saelens BE. Assessment of physical activity by selfreport: status, limitations, and future directions. Res Q Exerc Sport. 2000;71(2 Suppl):S1-14.

33. Shephard RJ. Limits to the measurement of habitual physical activity by questionnaires. Br J Sports Med. 2003;37(3):197-206.

34. Slaughter MH, Lohman TG, Boileau RA, et al. Skinfold equations for estimation of body fatness in children and youth. Hum Biol. 1988;60(5):709-23.

35. Smith JP. The impact of childhood health on adult labor market outcomes. Rev Econ Stat. 2009;91(3):478-89.

36. Stevenson B. Beyond the classroom: using Title IX to measure the return to high school sports. Rev Econ Stat. 2010;92:284-301.

37. Telama R, Leskinen E, Yang X. Stability of habitual physical activity and sport participation: a longitudinal tracking study. Scand J Med Sci Sports. 1996;6(6):371-8.

38. Telama R, Yang X, Leskinen E, et al. Tracking physical activity from early childhood through youth into adulthood. Med Sci Sports Exerc. 2014;46(5):955-62.

39. World Health Organization. Global Recommendations on Physical Activity for Health. 2010 [cited 2015 Sept 14]; 60 pp. Available from: http://whqlibdoc.who.int/publications/2010/9789241599979 eng.pdf?ua=1.

40. Yang X, Telama R, Hirvensalo M, Mattsson N, Viikari JS, Raitakari OT. The longitudinal effects of physical activity history on metabolic syndrome. Med Sci Sports Exerc. 2008;40(8):1424-31. 